\title{
Marsdenia tenacissima Extract Induces Autophagy and Apoptosis of Hepatocellular Cells via MIF/mToR Signaling
}

\author{
Shuai Lin, ${ }^{1}$ Qianwen Sheng, ${ }^{2}$ Xiaobin Ma, ${ }^{1}$ Shanli Li, ${ }^{1}$ Peng Xu, ${ }^{1}$ Cong Dai, ${ }^{3}$ Meng Wang, \\ Huafeng Kang $\mathbb{D}^{1}{ }^{1}$ and Zhijun Dai ${ }^{10}{ }^{1,4}$ \\ ${ }^{1}$ Department of Oncology, The Second Affiliated Hospital of Xi'an Jiaotong University, Xi'an 710004, China \\ ${ }^{2}$ Department of Oncology, Xi'an International Medical Center Hospital, Xi'an, China \\ ${ }^{3}$ Department of Thyroid Breast Surgery, Xi'an International Medical Center Hospital, Xi'an, China \\ ${ }^{4}$ Department of Breast Surgery, The First Affiliated Hospital, College of Medicine, Zhejiang University, Hangzhou 310003, China
}

Correspondence should be addressed to Huafeng Kang; kanghuafeng1973@126.com and Zhijun Dai; dzj0911@126.com

Received 28 August 2021; Revised 23 December 2021; Accepted 7 January 2022; Published 4 March 2022

Academic Editor: Yoshiki Mukudai

Copyright (c) 2022 Shuai Lin et al. This is an open access article distributed under the Creative Commons Attribution License, which permits unrestricted use, distribution, and reproduction in any medium, provided the original work is properly cited.

\begin{abstract}
Hepatocellular carcinoma (HCC) seriously endangers humans. In traditional Chinese medicine, Marsdenia tenacissima (MTE) has antiinflammatory, antiasthmatic, antihypertensive, and anticancer effects. This study reveals the antiproliferative effect of MTE on the HCC cells in vitro and provides a theoretical basis for the development and clinical application of anti-HCC agents. Methods. MHCC-97H and HepG2 cells were cultured in vitro and exposed to various concentrations and durations of MTE, and an MTT assay was used to detect the effects of MTE on cell proliferation. Transmission electron microscopy revealed the morphological changes in the two cell lines after MTE stimulation. The MTE effects on the apoptosis and cell cycle distribution of the cell lines were detected by flow cytometry. Western blotting and qRT-PCR were used to detect target gene expression at the protein and mRNA levels, respectively. Results. MTE reduced the viability of the MHCC-97H and HepG2 cells in a dose- and time-dependent manners $(P<0.05)$. Autophagic vesicles and apoptotic bodies were found in the MHCC-97H and HepG2 cells after MTE incubation, and the Annexin V-PI assay showed that the apoptotic rates of the cell lines increased with increasing MTE concentration $(P<0.05)$. Autophagy inducer rapamycin promoted the MTE-induced apoptotic rates of the cell lines, whereas autophagy inhibitor chloroquine inhibited the apoptotic rates. More cells in the $S$ phase were found in the two cell lines after MTE treatment $(P<0.05)$. After MTE incubation, MIF, CD47, and beclin-1 protein levels significantly increased. Furthermore, in the MTE group, Akt, mTOR, and caspase 3 expressions decreased; however, LC 3 expression increased, which was significantly different from the control group $(P<0.05)$. Conclusions. MTE inhibited proliferation and induced autophagy, apoptosis, and S phase cell cycle arrest in the MHCC-97H and HepG2 cells. These effects might be related to the activation of MIF and mTOR signaling inhibition.
\end{abstract}

\section{Introduction}

According to the GLOBOCAN statistics, in 2018, there were 841,000 new cases of hepatocellular carcinoma (HCC) and 782,000 HCC-related deaths worldwide, $48 \%$ of which were in China [1]. In recent decades, the incidence and mortality associated with HCC have been far ahead of those of many other cancers in China. It is the third most common cancer in China after lung and gastric cancer and ranks second in terms of mortality. Without timely intervention, people carrying hepatitis, especially hepatitis B, will develop cirrhosis, and eventually, HCC [2]. Additionally, aflatoxin, long-term heavy drinking, drinking polluted water, and genetic factors are also the risk factors for HCC [3]. Currently, HCC treatments are mainly based on surgical interventions and comprehensive therapies. However, because of the rapid progression of HCC, most patients are diagnosed in the middle and late stages of cancer when they seek medical attention, and only $20 \%$ of cases meet the surgical requirements [4]. Furthermore, low sensitivity to radiotherapy and chemotherapy, interventional therapy limitations, and a high recurrence rate mean that the five-year survival rate for HCC is low [5]. Therefore, exploring novel targeted drugs has become a top priority for medical practitioners. 
Traditional Chinese medicine is one of the main methods used in many cancer therapies, for example, HCC therapy. Combined with surgery, radiotherapy, chemotherapy, interventional therapy, and targeted therapy, Chinese medicine plays a vital role by focusing on strengthening the body and eliminating diseases. Marsdenia tenacissima (MTE) is a common Chinese herbal medicine produced in Yunnan and Guizhou, and it contains complex ingredients, such as alkaloids, steroidal ester glycosides, organic acids, resins, and polysaccharides. It is used to treat asthma, bronchitis, and other diseases [6]. The discovery of other positive effects means that it has been available in a tablet form and as an injection reagent called Xiaoaiping since 1984 [7]. Previous research found that butanol extracts of MTE enhanced patient immunity, while ethyl acetate and petroleum ether extracts were toxic to tumor cells, thus exerting anticancer effects. Pharmacological studies have shown that new C21 steroid glycosides isolated from MTE induce the aggregation, assembly, and stabilization of cell microtubules and inhibit the mitosis of cancer cells, thereby inhibiting cancer growth [8]. In addition, compared to advanced rectal cancer patients receiving chemotherapy alone, patients treated with chemotherapy and MTE had a higher response rate $(34.5 \%$ vs. $54.5 \%)$ and longer progression-free survival (6.43 vs. 7.97 months) [9]. Thus, MTE and its extractions are widely used as a monotherapy or as adjunctive therapy for gastric cancer, nonsmall cell lung cancer, esophageal cancer, and breast cancer [10-12]. However, there has been little basic or clinical research on MTE.

Apoptosis and autophagy are vital processes for cell death. Therefore, this study evaluated the effect of MTE on the proliferation, autophagy, apoptosis, and cell cycle distribution of two HCC cell lines (MHCC-97H and HepG2). The molecular mechanisms underlying MTE were also explored and elucidated.

\section{Methods}

2.1. Cells and Chemicals. The human HCC MHCC-97H and HepG2 cell lines were donated by other laboratories and cultured in Dulbecco's modified Eagle's medium (Gibco, Carlsbad, CA, USA), containing $10 \%$ fetal bovine serum (FBS; Gibco) and $0.1 \%$ penicillin-streptomycin solution (Gibco) in a humidified $5 \% \mathrm{CO}_{2}$ environment at $37^{\circ} \mathrm{C}$. MTE was purchased from Sanhome Pharmaceutical Limited Company.

2.2. Cell Proliferation Assay. A 3-(4,5)-dimethylthiahiazo (-z-y1)-3,5-di-phenytetrazoliumromide (MTT) assay was performed to explore the effect of MTE on HCC cell proliferation. In brief, the MHCC-97H and HepG2 cells were inoculated at a density of $8 \times 10^{3}$ cells $/ 100 \mu \mathrm{L}$ with five replicate wells in a 96-well plate and stimulated with various concentrations of $\operatorname{MTE}(0,12.5,25,50,100,200$, and $400 \mathrm{mg} / \mathrm{mL}$ ) for $24 \mathrm{~h}, 48 \mathrm{~h}$, and $72 \mathrm{~h}$. After washing with phosphate-buffered saline (PBS), $20 \mu \mathrm{L}$ of MTT solution $(5 \mathrm{mg} / \mathrm{mL})$ was added to each well, and the plates were incubated for $4 \mathrm{~h}$ at $37^{\circ} \mathrm{C}$ in a humidified $5 \% \mathrm{CO}_{2}$ incubator (Thermo Fisher Scientific, Waltham, MA, USA). Finally, after discarding the supernatant, $160 \mu \mathrm{L}$ of dimethyl sulfoxide (DMSO) was added to each well and the plates were shaken at low speed for $10 \mathrm{~min}$. Optical density (OD) values were measured using a microplate reader at $490 \mathrm{~nm}$.

2.3. Electron Microscopy. MTE-treated MHCC-97H and HepG2 cells were observed by electron microscopy to determine whether autophagy and apoptosis occurred. Firstly, MHCC-97H and HepG2 cells were incubated with 0, 35, and $50 \mathrm{mg} / \mathrm{mL}$ MTE for $48 \mathrm{~h}$. After trypsinization and centrifugation, the cells were collected and fixed in $0.05 \mathrm{M}$ cacodylate buffer $(\mathrm{pH}=7.0)$ supplemented with $2.5 \%$ glutaraldehyde and $2.5 \%$ formaldehyde. Then, the cells were kept in $1 \%$ OsO4 cacodylate buffer for $24 \mathrm{~h}$ at $4^{\circ} \mathrm{C}$, rinsed once with the same buffer, dehydrated with acetone, and embedded in epoxy resin. Ultrathin sections $(70 \mathrm{~nm})$ were obtained using a Leica Ultracut UCT ultramicrotome, stained with lead citrate and uranyl acetate, and observed using electron microscopy.

2.4. Cell Apoptosis Analysis. The MHCC97-H and HepG2 cells were treated with different concentrations of MTE, MTE plus the autophagy activator rapamycin (Rapa) (MCE, Monmouth Junction, NJ, USA), or an autophagy inhibitor (chloroquine [CQ]; Sigma-Aldrich, Saint Louis, MO, USA) for $48 \mathrm{~h}$. Then, the cells in the supernatant and adherent cells were harvested and washed twice with PBS. The cells $\left(1 \times 10^{6}\right)$ were suspended in $100 \mu \mathrm{L}$ binding buffer and stained with FITC-labeled Annexin-V $(5 \mu \mathrm{L})$ and propidium iodide $(5 \mu \mathrm{L})$ without light for $10 \mathrm{~min}$. The apoptotic rate of the cells was examined by flow cytometry (FCM; Becton Dickinson and Company, East Rutherford, NJ, USA).

2.5. Cell Cycle Analysis. MTE-treated MHCC-97H and HepG2 cells were collected and fixed in cold 70\% ethanol overnight at $4^{\circ} \mathrm{C}$. Then, the cells were washed once with PBS and incubated with a staining working solution (RNase A: propidium iodide $=1: 9$ ) for $30 \mathrm{~min}$ in the dark at room temperature. Finally, the cell cycle distribution of the HCC cells was assessed using FCM.

2.6. Western Blotting (WB) Assay. The MHCC-97H cells were exposed to $0,17.5,35$, and $70 \mathrm{mg} / \mathrm{mL}$ MTE for $48 \mathrm{~h}$, and protein lysates were collected as described in our previous study [13]. The proteins were separated by $10 \%$ sodium dodecyl sulfate-polyacrylamide gel electrophoresis, transferred to polyvinylidene fluoride membranes, and then they blocked with Tris-buffered saline with $0.1 \%$ Tween 20 containing $5 \%$ bovine serum albumin for $2 \mathrm{~h}$ at room temperature. After treatment with primary antibodies at $4^{\circ} \mathrm{C}$ overnight, the membranes were incubated with secondary antibodies for $1 \mathrm{~h}$ at room temperature. The primary antibodies used in the WB assay were as follows: rabbit antimicrotubule-associated protein 1 light chain 3 I/II (LC3 I/II; 4108, Cell Signaling Technology, Danvers, MA, USA [CST]), 
rabbit anticaspase 3 (9662, CST), rabbit antimacrophage migration inhibitory factor (MIF) (87501, CST), rabbit antiCD74 (63000, CST), rabbit antibeclin-1 (3495, CST), mouse anti- $\beta$-actin (3700, CST), rabbit antiserine/threonine kinase (Akt; 4691, CST), and rabbit antimammalian target of rapamycin (mTOR; 2983, CST).

2.7. Quantitative Real-Time Polymerase Chain Reaction ( $q R T$ $P C R)$. The MHCC97-H and HepG2 cells were stimulated with various concentrations of MTE for $48 \mathrm{~h}$. The total RNA content from the treated cells was extracted using TRIzol (Sigma, USA) and used to synthesize cDNA. The cDNA was subsequently used for PCR amplification to detect gene expression at the mRNA level. The $2^{-\Delta \Delta C t}$ method was used to analyze the mRNA expressions of Akt, mTOR, LC 3, caspase 3 , and $\beta$-actin. The sequences of the primers used are listed in Table 1.

2.8. Statistics. All experiments were repeated at least three times. The results are displayed as mean standard \pm deviation $(\bar{x} \pm$ SD) and were analyzed using SPSS software (version 21.0, IBM Corp., Armonk, NY, USA). Differences between multiple groups were compared by one-way analysis of variance (ANOVA), and the significant difference levels were ${ }^{*} P<0.05$, and ${ }^{*}{ }^{*} P<0.01$.

\section{Results}

3.1. MTE Inhibits the Proliferation of MHCC-97H and HepG2 Cells. The human HCC MHCC-97H cells with high invasive potential and the HepG2 cells with a low invasive potential were treated with various concentrations of MTE for different durations (24, 48, and $72 \mathrm{~h}$ ). As shown in Tables 2 and 3 , even at a low concentration $(12.5 \mathrm{mg} / \mathrm{mL})$, MTE treatment significantly decreased the viability of the MHCC-97H and HepG2 cells. In addition, the cell viability rates for the MHCC97-H and HepG2 cells decreased sharply as the MTE concentration and treatment time increased (Figures 1(a) and 1(b)). Furthermore, the MHCC-97H cells seemed more sensitive to MTE administration than HepG2 cells, as evidenced by the lower survival rate of the MHCC-97H cells under the same conditions.

The cellular morphology of the MHCC-97H and HepG2 cells was observed under a microscope after they had been treated with $35 \mathrm{mg} / \mathrm{mL}$ and $50 \mathrm{mg} / \mathrm{mL}$ MTE, respectively, for $48 \mathrm{~h}$. The number of live cells declined in the treatment group compared to that of the control group, their cell volumes decreased, and the cells shrank and became rounded (Figures $1(\mathrm{c})$ and $1(\mathrm{~d})$ ). In addition, we observed cell debris and increased particles in the cytoplasm, and cell chromatin had gathered close to the nuclear membrane, which suggested pyknotic cell death in the MTE treatment group.

3.2. MTE Induces Autophagy and Apoptosis of MHCC-97H and HepG2 Cells. The MHCC-97H and HepG2 cells were observed using electron microscopy observations after they had been treated with 35 and $50 \mathrm{mg} / \mathrm{mL}$ MTE for $48 \mathrm{~h}$, respectively. The results revealed that the chromatin in the MHCC97-H and HepG2 cells was evenly distributed in the control group (Figure 2(a)). MTE treatment induced the formation of autophagosomes and autophagosome-lysosome structures in the MHCC97-H and HepG2 cells (Figure 2(b)). Furthermore, apoptotic bodies were also observed in the treated cells (Figure 2(c)). An Annexin-V/PI assay was used to evaluate the apoptotic rates of the MHCC$97 \mathrm{H}$ and HepG2 cells induced by MTE treatment. Figure 3 shows that the percentage of apoptotic MHCC-97H and HepG2 cells increased as the MTE concentration rose. The $17.5,35$, and $70 \mathrm{mg} / \mathrm{mL}$ MTE concentrations resulted in the apoptotic rates of $7.98 \pm 0.30 \%, 9.72 \pm 1.05 \%$, and $16.7 \pm 1.37 \%$ in the MHCC $97-\mathrm{H}$ cells, respectively, while $25 \mathrm{mg} / \mathrm{mL}, 50 \mathrm{mg} / \mathrm{mL}$, and $100 \mathrm{mg} / \mathrm{mL}$ MTE led to the apoptotic rates of $13.46 \pm 1.19 \%, 17.63 \pm 0.99 \%$, and $25.77 \pm 1.14 \%$ in the HepG2 cells, respectively. Statistical differences were found between the MHCC-97H and HepG2 treatment and control groups.

To explore the relationship between autophagy and apoptosis induced by MTE treatment, the MHCC-97H and HepG2 cells were incubated with MTE, MTE combined with an autophagy activator (Rapa), or an autophagy inhibitor (CQ) for $48 \mathrm{~h}$, and the apoptotic rates were examined by FCM. Figure 4 shows that in the presence of MTE, Rapa increased the apoptotic rate of the two cell lines. However, additional CQ reduced the apoptotic rate. The above results suggest that MTE not only induces autophagy and apoptosis but also promotes apoptosis.

3.3. MTE Induces S Phase Cell Cycle Arrest in MHCC-97H and HepG2 Cells. The PI single staining assay was used to detect the cell cycle distribution of the two types of HCC cells. With MHCC-97H cells, the percentage of cells in the S phase increased remarkably from $12.55 \%$ to $17.78 \%, 20.74 \%$, and $23.61 \%$ after $17.5,35$, and $70 \mathrm{mg} / \mathrm{mL}$ MTE stimulation, respectively (Figures 5(a) and 5(b)). The MTE treatment at doses of 25,50 , and $100 \mathrm{mg} / \mathrm{mL}$ caused $18.54 \%, 22.10 \%$, and $24.62 \%$ of HepG2 cells to be arrested in the S phase, respectively (Figures 5(c) and 5(d)). Thus, the results showed that MTE might play a role by inducing the $S$ phase cell cycle arrest.

3.4. MTE Induces the Autophagy of HCC Cells by Inhibiting the Akt/mTOR Pathway via MIF. Figure 6(a) shows that the increased expression of beclin-1 and the ratio of LC 3 II to LC3 I reflect the occurrence of autophagy, whereas the decreased ratio of cleaved caspase 3 to caspase 3 in MTEstimulated MHCC-97H cells reflects the occurrence of apoptosis. Additionally, the protein expressions of MIF and its molecular receptor CD74 in the MHCC-97H cells significantly increased after MTE treatment (Figure 6(a)). MIF is reported to be an upstream regulator of the mTOR signaling pathway, and the mTOR pathway is now considered a target for cancer therapy. Therefore, the protein and mRNA levels of Akt and mTOR in the MHCC-97H and HepG2 cells were quantified by WB and qRT-PCR. The results revealed that an 
Table 1: Primers used in the experiment.

\begin{tabular}{|c|c|c|}
\hline Gene & & Primer sequence $\left(5^{\prime}-3^{\prime}\right)$ \\
\hline Akt & $\begin{array}{l}\text { Forward } \\
\text { Reverse }\end{array}$ & $\begin{array}{l}5^{\prime} \text { - CAGGATGTGGACCAACGTGA - } 3^{\prime} \\
5^{\prime}-\text { AAGGTGCGTTCGATGACAGT - } 3^{\prime}\end{array}$ \\
\hline mTOR & $\begin{array}{l}\text { Forward } \\
\text { Reverse }\end{array}$ & $\begin{array}{c}5^{\prime} \text {-CCACTGGTCTATGCCATCCC -3' } \\
5^{\prime} \text {-AATGTAGGAGAACGTGGGGC -3' }\end{array}$ \\
\hline LC3 & $\begin{array}{l}\text { Forward } \\
\text { Reverse }\end{array}$ & $\begin{array}{l}5^{\prime}-\text { TTCCGAGTTGCTGACTGACC -3' } \\
5^{\prime} \text {-CCCTTGTAGCGCTCGATGAT - } 3^{\prime}\end{array}$ \\
\hline caspase 3 & $\begin{array}{l}\text { Forward } \\
\text { Reverse }\end{array}$ & $\begin{array}{c}5^{\prime} \text {-TGCTATTGTGAGGCGGTTGT }-3^{\prime} \\
5^{\prime}-\text { TCCAGAGTCCATTGATTCGCT }-3^{\prime}\end{array}$ \\
\hline$\beta$-Actin & $\begin{array}{l}\text { Forward } \\
\text { Reverse }\end{array}$ & $\begin{array}{l}5^{\prime} \text { - GACAGTCAGCCGCATCTTCT -3' } \\
5^{\prime} \text { - GCGCCCAATACGACCAAATC -3' }\end{array}$ \\
\hline
\end{tabular}

TABLE 2: The effect of MTE on MHCC-77H cell proliferation $(\bar{x} \pm S D)$.

\begin{tabular}{|c|c|c|c|c|c|c|}
\hline \multirow{2}{*}{ Concentration $(\mathrm{mg} / \mathrm{mL})$} & \multicolumn{2}{|c|}{$24 \mathrm{~h}$} & \multicolumn{2}{|c|}{$48 \mathrm{~h}$} & \multicolumn{2}{|c|}{$72 \mathrm{~h}$} \\
\hline & OD & SR (\%) & OD & SR (\%) & OD & SR $(\%)$ \\
\hline 0 & $0.346 \pm 0.157$ & 100 & $0.337 \pm 0.122$ & 100 & $0.448 \pm 0.272$ & 100 \\
\hline 12.5 & $0.300 \pm 0.142$ & $86.5^{*}$ & $0.261 \pm 0.129$ & $73.3^{* *}$ & $0.294 \pm 0.169$ & $67.4^{* *}$ \\
\hline 25.0 & $0.286 \pm 0.138$ & $82.3^{*}$ & $0.207 \pm 0.099$ & $58.6^{* *}$ & $0.214 \pm 0.137$ & $46.1^{* *}$ \\
\hline 50.0 & $0.255 \pm 0.116$ & $73.9^{* *}$ & $0.169 \pm 0.107$ & $44.5^{* *}$ & $0.117 \pm 0.052$ & $29.9^{* *}$ \\
\hline 100.0 & $0.142 \pm 0.066$ & $40.4^{* *}$ & $0.057 \pm 0.009$ & $18.4^{* *}$ & $0.066 \pm 0.019$ & $19.1^{* *}$ \\
\hline 200.0 & $0.060 \pm 0.034$ & $17.6^{* *}$ & $0.040 \pm 0.006$ & $13.1^{* *}$ & $0.055 \pm 0.016$ & $16.0^{* *}$ \\
\hline 400.0 & $0.041 \pm 0.019$ & $11.9^{* *}$ & $0.033 \pm 0.011$ & $9.8^{* *}$ & $0.044 \pm 0.020$ & $11.2^{* *}$ \\
\hline
\end{tabular}

OD: optical density, SR: survival rate, ${ }^{*} P<0.05$, and ${ }^{* *} P<0.01$.

TABle 3: The effect of MTE on HepG2 cell proliferation $(\bar{x} \pm$ SD).

\begin{tabular}{|c|c|c|c|c|c|c|}
\hline \multirow{2}{*}{ Concentration $(\mathrm{mg} / \mathrm{mL})$} & \multicolumn{2}{|c|}{$24 \mathrm{~h}$} & \multicolumn{2}{|c|}{$48 \mathrm{~h}$} & \multicolumn{2}{|c|}{$72 \mathrm{~h}$} \\
\hline & OD & SR (\%) & OD & SR (\%) & OD & SR (\%) \\
\hline 0 & $0.348 \pm 0.052$ & 100 & $0.344 \pm 0.068$ & 100 & $0.344 \pm 0.024$ & 100 \\
\hline 12.5 & $0.310 \pm 0.041$ & $89.3^{*}$ & $0.303 \pm 0.053$ & $88.5^{*}$ & $0.292 \pm 0.021$ & $84.7^{*}$ \\
\hline 25.0 & $0.299 \pm 0.045$ & $86.1^{*}$ & $0.270 \pm 0.051$ & $78.5^{*}$ & $0.241 \pm 0.007$ & $70.3^{* *}$ \\
\hline 50.0 & $0.230 \pm 0.023$ & $66.9^{*}$ & $0.185 \pm 0.022$ & $54.6^{* *}$ & $0.162 \pm 0.006$ & $47.3^{* *}$ \\
\hline 100.0 & $0.147 \pm 0.042$ & $42.9^{* *}$ & $0.083 \pm 0.012$ & $24.4^{* *}$ & $0.065 \pm 0.0003$ & $19.0^{* *}$ \\
\hline 200.0 & $0.105 \pm 0.014$ & $30.9^{*}$ & $0.070 \pm 0.011$ & $20.4^{*}$ & $0.055 \pm 0.004$ & $16.1^{*}$ \\
\hline 400.0 & $0.080 \pm 0.017$ & $23.1^{*}$ & $0.059 \pm 0.010$ & $17.4^{*}$ & $0.046 \pm 0.000$ & $13.5^{*}$ \\
\hline
\end{tabular}

OD: optical density, SR: survival rate, ${ }^{*} P<0.05$, and ${ }^{* *} P<0.01$.

increase in the MTE concentration led to sharp decreases in the expressions of Akt and mTOR (Figures 6(b)-6(d)). Therefore, MTE-induced autophagy might be related to the inhibition of Akt/mTOR signaling via MIF.

\section{Discussion}

Autophagy is a normal cellular process in the body that provides a material basis for the development and maintenance of cellular homeostasis. Damaged or aged organelles and misfolded or mutated proteins are wrapped in the double-layer membrane of the rough endoplasmic reticulum, and the formed autophagosomes are fused with lysosomes to form a monolayer of autophagolysosomes to degrade these components [14]. Autophagy is closely related to cancer, and its effects on cancer are controversial. Autophagy promotes cell survival under stress conditions, such as hypoxia and pathogen infection [15]. Inhibiting autophagy suppresses the growth of pancreatic tumors in vivo and in vitro [16]. Hydroxychloroquine, an autophagy inhibitor, has been shown to increase tumor cell death alone or exert stronger tumor-killing potential in combination with other agents in preclinical studies [17]. Many drugs with the potential to induce autophagy have been widely used as therapeutic intervention agents during cancer treatment [18]. Yan et al. found that baicalein has an antibreast cancer effect by inducing autophagy in the breast cancer cells [19]. Nano-C60- and cysteamine-activated autophagy reverses the resistance of the MCF-7 cells to doxorubicin and enhances the efficacy of chemotherapy [20]. In this study, we found that MTE treatment induced the formation of autophagosomes and increased the mRNA level of the LC 3 gene in the MHCC-97H and HepG2 cells, indicating that MTE might suppress the HCC cell growth by inducing autophagy.

Apoptosis is the autonomous programmed death of cells. It is controlled by various genes and plays an important role in the growth and development of humans [21]. Drugs, such 


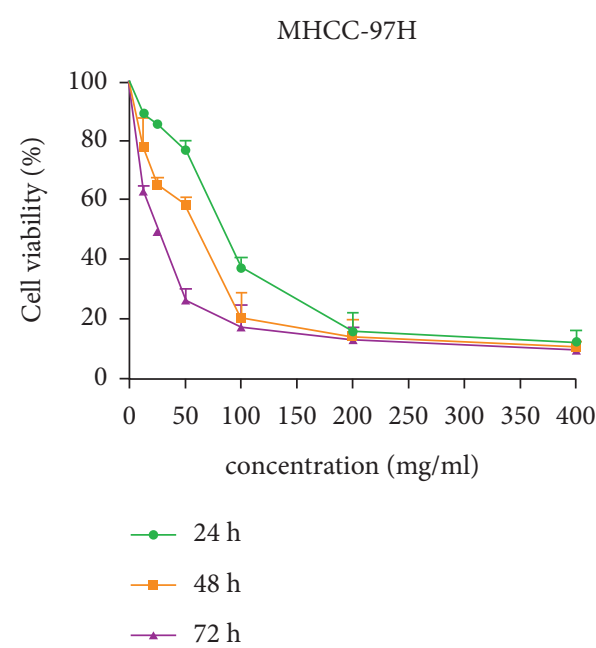

(a)

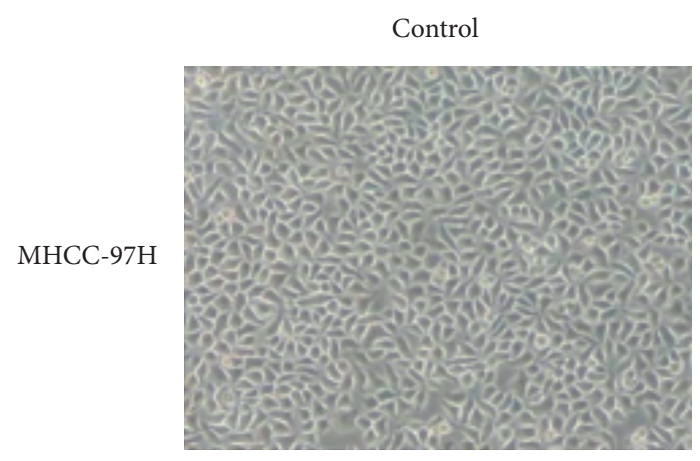

(c)

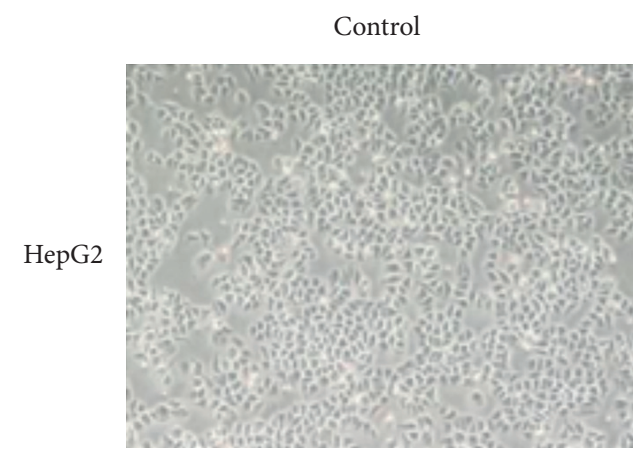

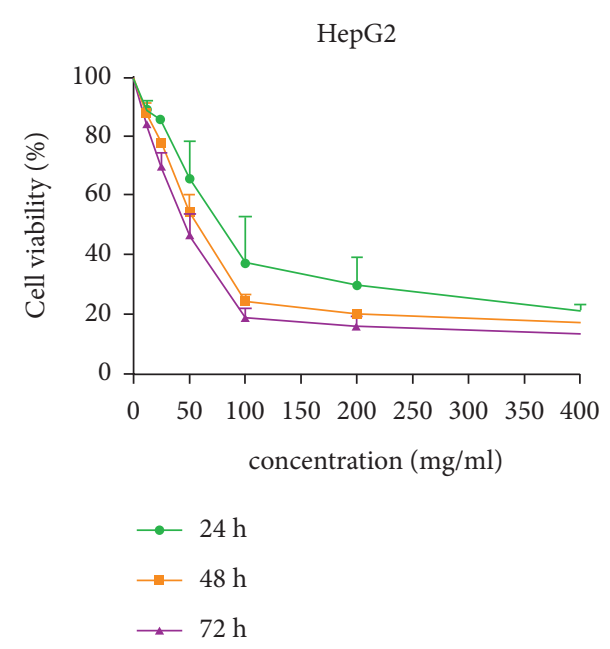

(b)

MTE

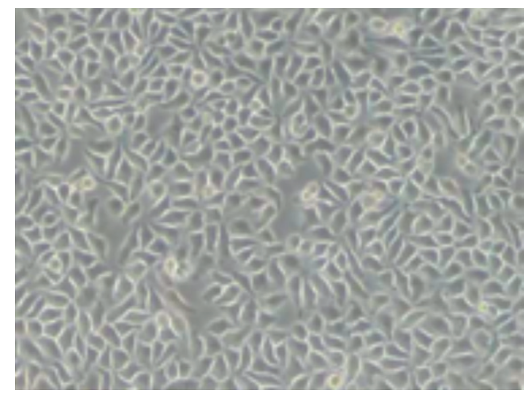

MTE

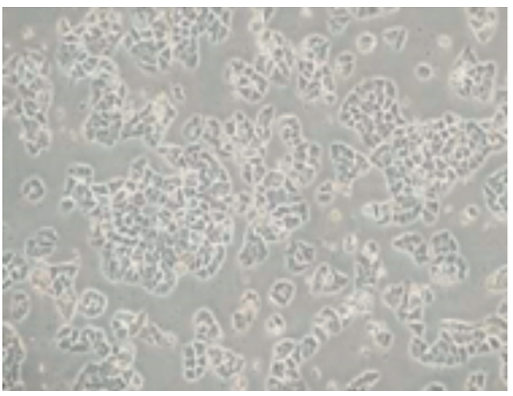

(d)

FiguRE 1: MTE suppressed the proliferation of the MHCC-97H and HepG2 cells in a dose- and time-dependent manner. (a, b) The MHCC$97 \mathrm{H}$ and HepG2 cells were stimulated with various concentrations of MTE $(0,12.5,25,50,100,200$, and $400 \mathrm{mg} / \mathrm{mL})$ for $24 \mathrm{~h}, 48 \mathrm{~h}$, and $72 \mathrm{~h}$. The cell viabilities of (a) the MHCC-97H and (b) HepG2 were assessed by MTT assay. (c) The cellular morphologies of the MHCC-97 cells in the control and MTE treatment group $(35 \mathrm{mg} / \mathrm{mL})$ were observed using electron microscopy $(\times 40)$. (d) The cellular morphologies of the HepG2 cells in the control and MTE treatment group $(50 \mathrm{mg} / \mathrm{mL})$ were observed using electron microscopy $(\times 40)$. $n=5$.

as chemotherapeutics, can induce the apoptosis of tumor cells to suppress tumor growth [22]. When apoptosis occurs, it is usually accompanied by changes in cell morphology, such as nuclear condensation, high chromatin condensation, marginalization, and chromosome breakage, and apoptotic bodies are usually found during the late stage of cancer progression. In our study, we found that MTE treatment induced the above-mentioned changes in cell morphology and apoptotic bodies after observing cells using an inverted microscope and a transmission electron microscope. The FCM assay further confirmed the occurrence of apoptosis in the MHCC-97H and HepG2 cells after MTE incubation. Previous studies have found that autophagy has a dual effect because it inhibits and promotes tumor growth under different conditions. Thus, we investigated the association between autophagy and apoptosis induced by MTE incubation. Combined with autophagy inducer (Rapa), MTE treatment resulted in more apoptotic cells than MTE alone, 

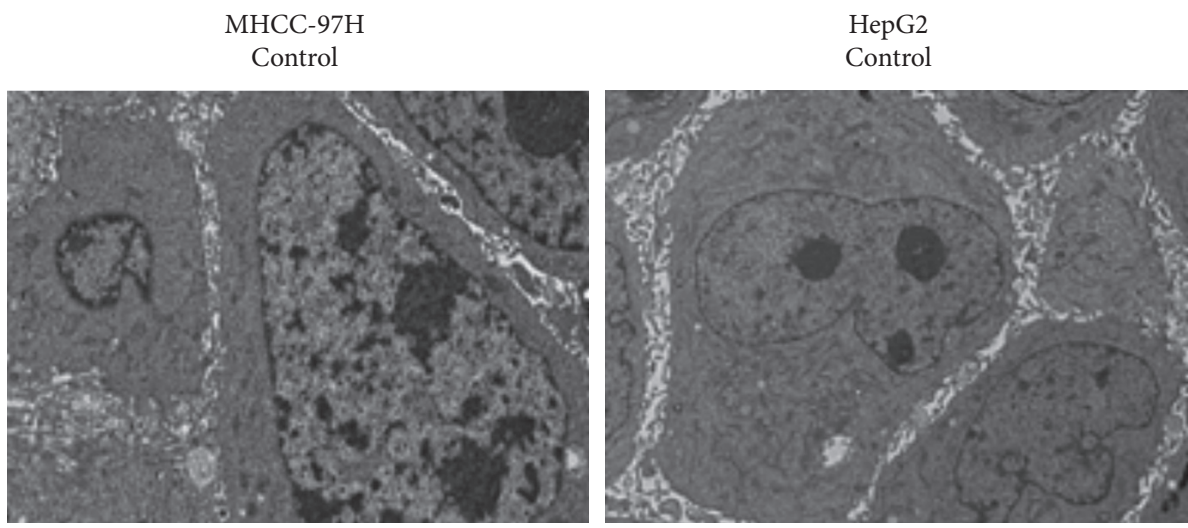

(a)
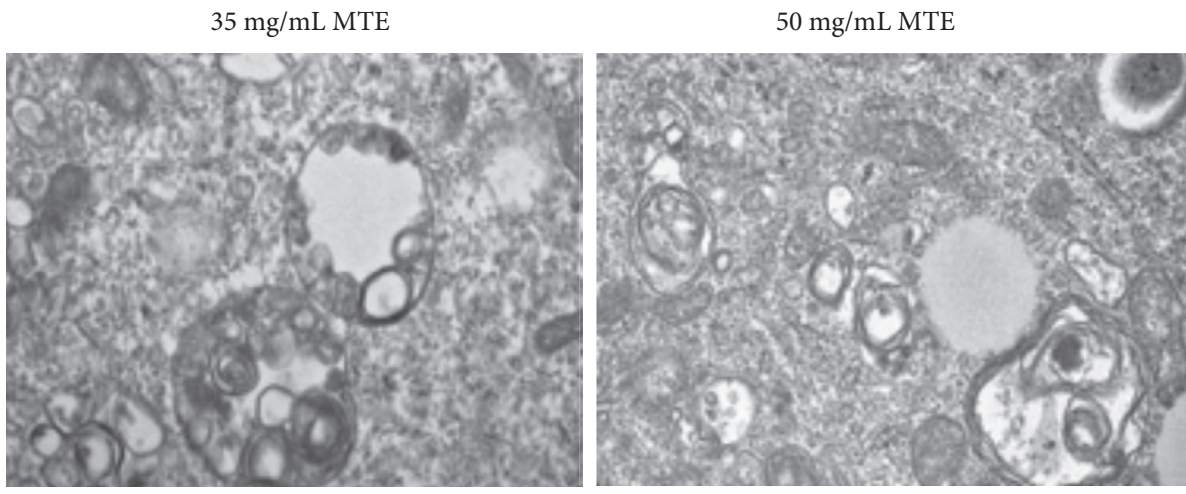

(b)

$35 \mathrm{mg} / \mathrm{mL}$ MTE

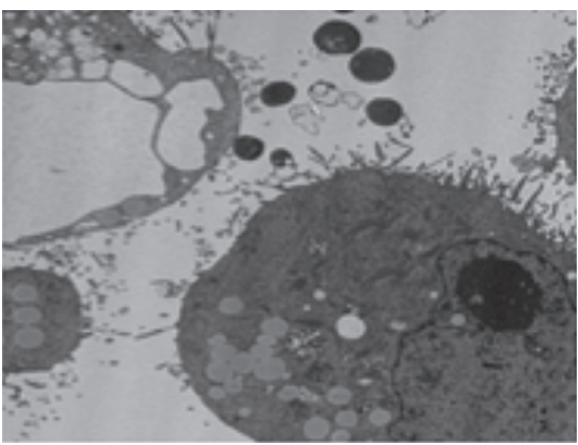

$50 \mathrm{mg} / \mathrm{mL}$ MTE

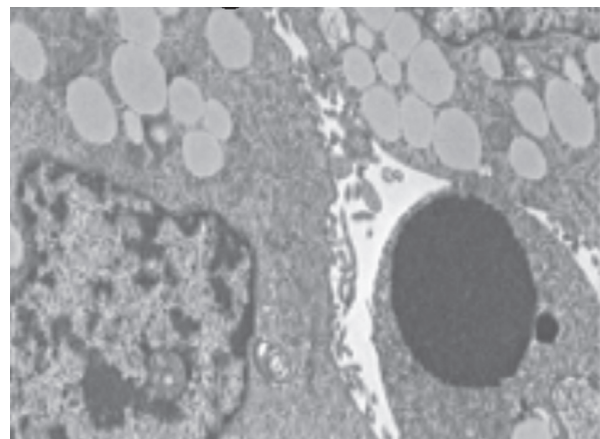

(c)

FIGURE 2: MTE induced autophagy and apoptosis of the MHCC-97H and HepG2 cells. (a) Normal morphologies of the MHCC-97H and HepG2 cells were observed using transmission electron microscopy. (b) $35 \mathrm{mg} / \mathrm{mL}$ and $50 \mathrm{mg} / \mathrm{mL}$ MTE treatment induced the formation of autophagosomes and autophagosome-lysosome structures in the MHCC-97H and HepG2 cells, respectively. (c) $35 \mathrm{mg} / \mathrm{mL}$ and $50 \mathrm{mg} / \mathrm{mL}$ MTE treatment induced the formation of apoptotic bodies in the MHCC-97H and HepG2 cells, respectively.

however, in the presence of an autophagy inhibitor (CQ), MTE treatment reduced the number of apoptotic cells compared to MTE alone, suggesting that MTE-induced autophagy promoted MTE-induced apoptosis, thereby exerting a strong inhibitory effect on the growth of HCC cells.

MIF was first discovered in the culture medium of active $\mathrm{T}$ lymphocytes and macrophages, and it mediates the innate and adaptive immune system to exert immune-regulatory functions [23]. Although recent studies have indicated that MIF is involved in the regulation of autophagy in tumor cells, its role is unclear $[24,25]$. Silencing MIF reversed the conversion of autophagy marker LC 3-I to LC 3-II and induced mitochondrial autophagy [26]. However, recombinant human MIF increased autophagy in glioblastoma cells, and the knockout of endogenous MIF inhibited autophagy [27]. In breast cancer cells, MIF expression promotes autophagy, thereby inhibiting tumorigenesis and enhancing sensitivity to chemotherapeutic drugs [28]. In this study, we found that MTE treatment induced autophagy and elevated MIF and CD47 expressions in the HCC cells, indicating that MIF might participate in the MTE-stimulated autophagy process. 
Control

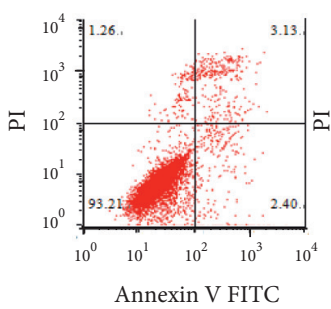

Annexin V FITC

Control

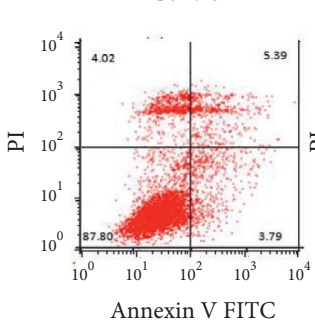

$17.5 \mathrm{mg} / \mathrm{ml} \mathrm{MTE}$

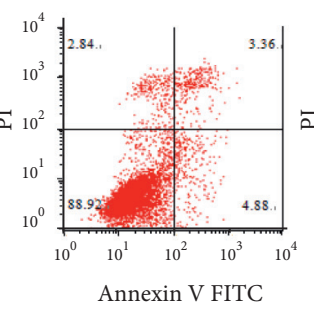

$35 \mathrm{mg} / \mathrm{ml} \mathrm{MTE}$
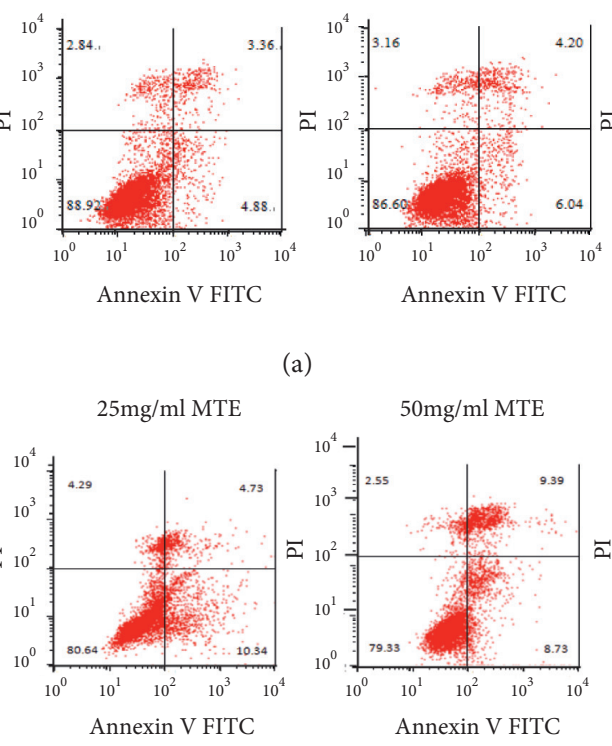

(a)

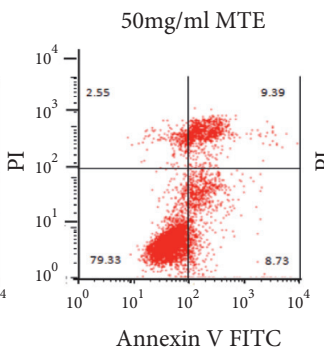

$70 \mathrm{mg} / \mathrm{ml} \mathrm{MTE}$

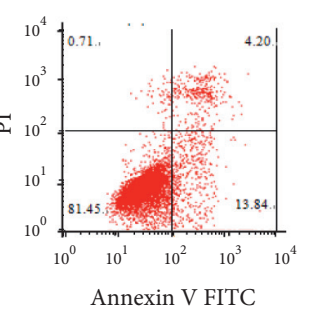

Annexin V FITC

$100 \mathrm{mg} / \mathrm{ml} \mathrm{MTE}$

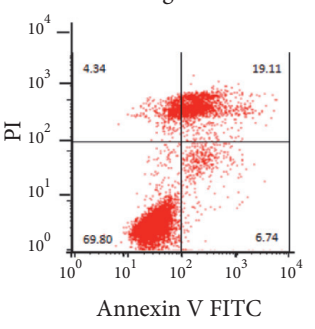

(c)

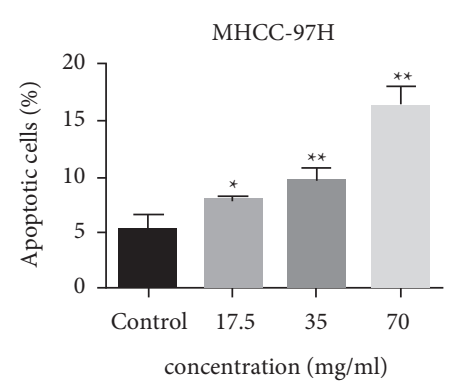

(b)

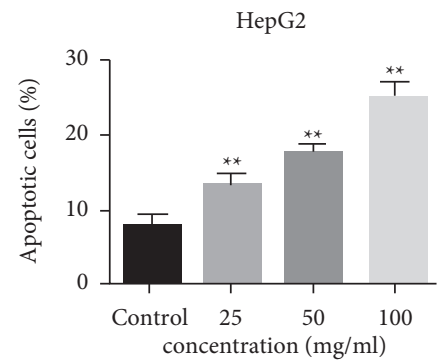

(d)

Figure 3: MTE induced apoptosis of the MHCC-97H and HepG2 cells in a dose-dependent manner. (a) Apoptotic rates for the MHCC-97H cells after MTE treatment (17.5 mg/mL, $35 \mathrm{mg} / \mathrm{mL}$, and $70 \mathrm{mg} / \mathrm{mL}$ ) were detected by FCM. (b) Quantitative data for (a). (c) Apoptotic rates for the HepG2 cells after MTE treatment $(25 \mathrm{mg} / \mathrm{mL}, 50 \mathrm{mg} / \mathrm{mL}$, and $100 \mathrm{mg} / \mathrm{mL}$ ) were detected by FCM. (d) Quantitative data for (c). $n=3$.
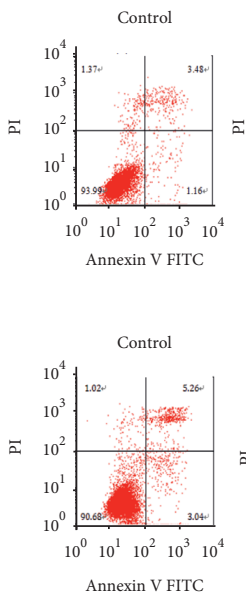
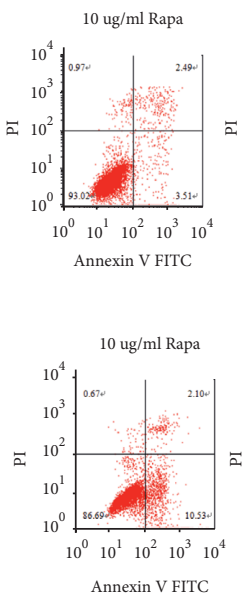
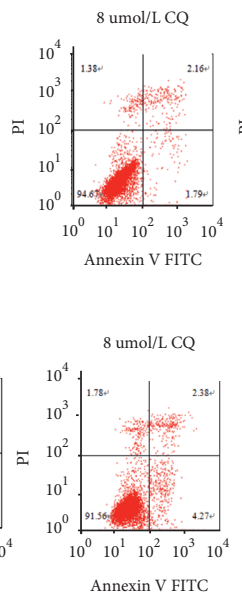

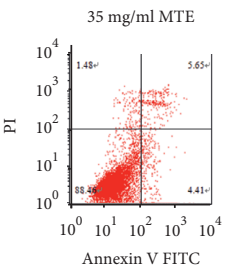

(a)

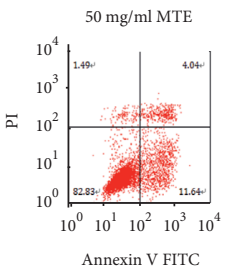

(c)
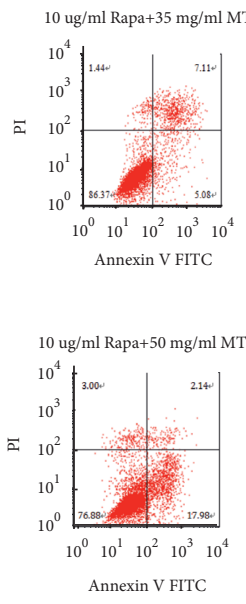

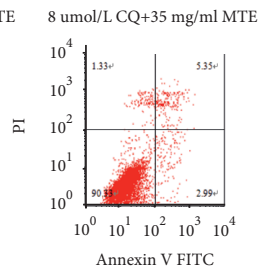

Annexin V FITC

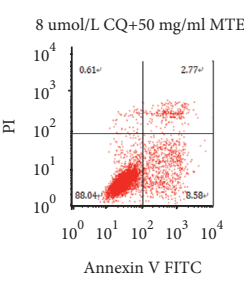

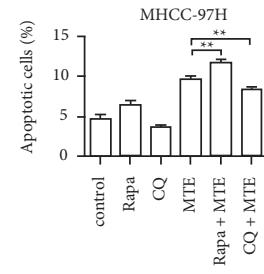

(b)

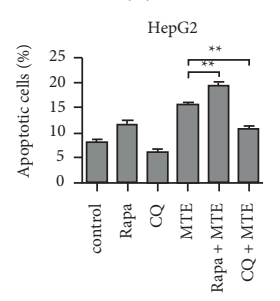

(d)

FIGURE 4: Relationship between autophagy and apoptosis induced by MTE treatment. (a) The MHCC-97H cells were treated with Rapa $(10 \mu \mathrm{g} / \mathrm{mL})$, CQ $(8 \mu \mathrm{mol} / \mathrm{L}), \operatorname{MTE}(35 \mathrm{mg} / \mathrm{mL})$, Rapa $(10 \mu \mathrm{g} / \mathrm{mL})$ plus MTE $(35 \mathrm{mg} / \mathrm{mL})$, or CQ $(8 \mu \mathrm{mol} / \mathrm{L}) \mathrm{plus} \mathrm{MTE}(35 \mathrm{mg} / \mathrm{mL})$. The apoptotic cells were detected by FCM. (b) Quantitative data for (a). (c) The HepG2 cells were treated with Rapa $(10 \mu \mathrm{g} / \mathrm{mL})$, CQ ( $8 \mu \mathrm{mol} / \mathrm{L})$, MTE $(50 \mathrm{mg} / \mathrm{mL})$, Rapa $(10 \mu \mathrm{g} / \mathrm{mL})$ plus MTE $(50 \mathrm{mg} / \mathrm{mL})$, or CQ $(8 \mu \mathrm{mol} / \mathrm{L})$ plus MTE $(50 \mathrm{mg} / \mathrm{mL})$. The apoptotic cells were detected by FCM. (d) Quantitative data for (c). $n=3$.

The phosphatidylinositol-4,5-bisphosphate 3-kinase (PI3K)-Akt-mTOR pathway not only regulates the growth, proliferation, differentiation, and apoptosis of normal cells but also regulates the occurrence and development of cancer and its sensitivity to different therapies [29, 30]. Akt and mTOR were found to be overexpressed in HCC tissues, and their expression was positively associated with the degree of malignancy [31]. In addition, normal cells can transform into HCC cells by activating mTOR signaling [32]. Drugs, such as buparlisib, everolimus, and perifosine, which target the PI3K/ $\mathrm{Akt} / \mathrm{mTOR}$ pathway, have the potential to inhibit survival pathways and induce apoptosis and autophagy in cancer cells, and they have been found to have favorable antitumor efficacies in clinical trials [33]. Similar to these results, we found that treatment of the MHCC-97H and HepG2 cells with MTE decreased the expressions of Akt and $\mathrm{mTOR}$ in a dose-dependent manner. These results 

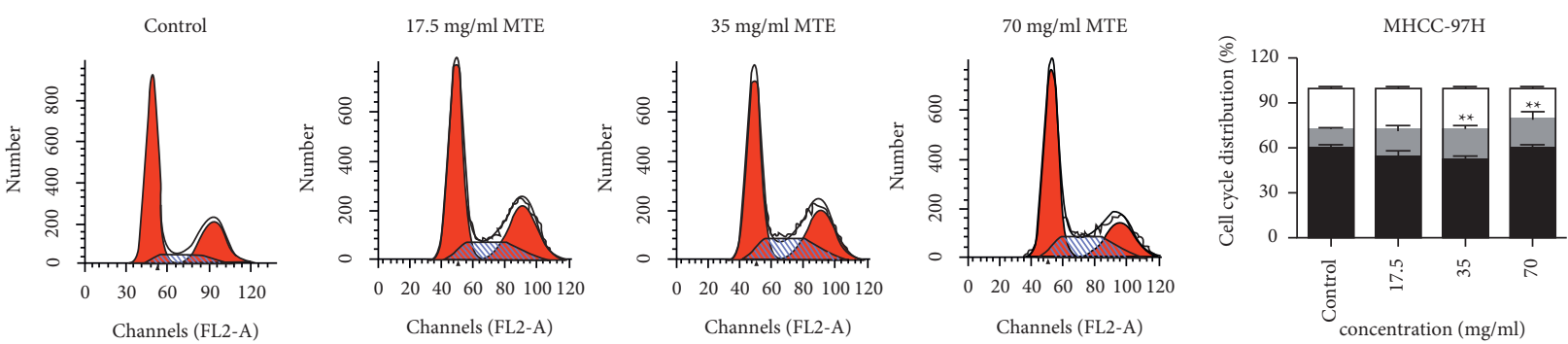

$$
\begin{aligned}
& \square \mathrm{G} 2 / \mathrm{M} \\
& \mathrm{S} \\
& \square \mathrm{G} 0 / 1
\end{aligned}
$$

(a)
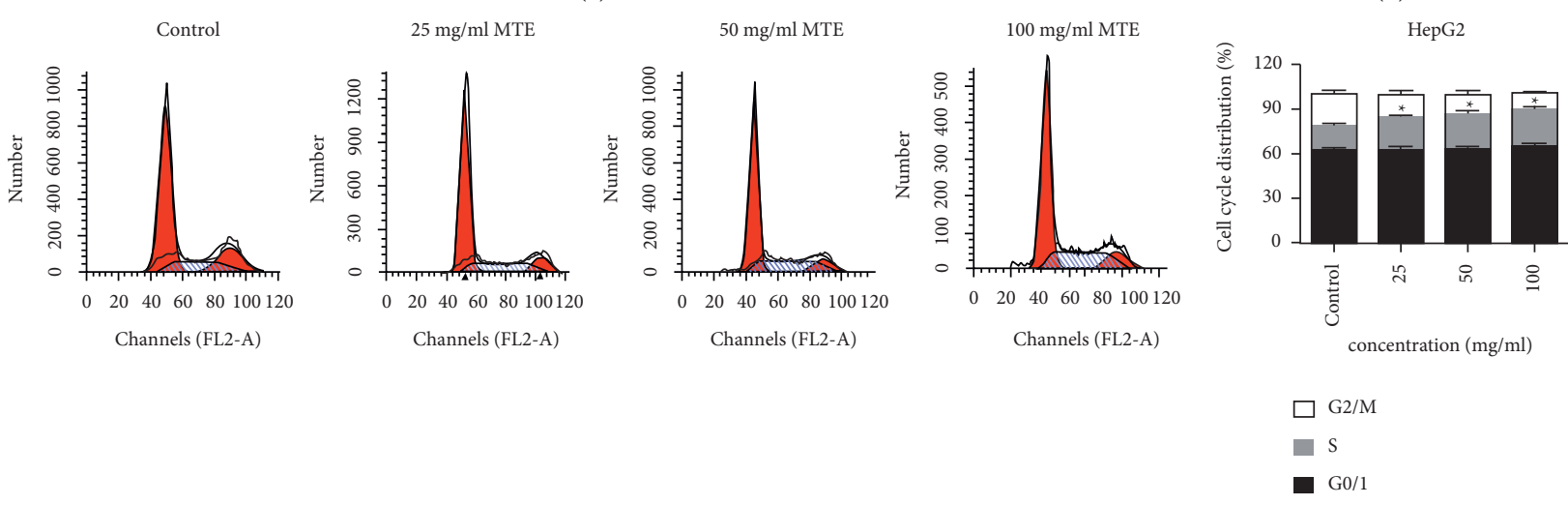

(c)

(d)

Figure 5: MTE induced the S cell cycle arrest in the MHCC-97H and HepG2 cells. (a) Cell cycle distributions of the MHCC-97H cells after MTE treatment $(17.5 \mathrm{mg} / \mathrm{mL}, 35 \mathrm{mg} / \mathrm{mL}$, and $70 \mathrm{mg} / \mathrm{mL}$ ) were detected by FCM. (b) Quantitative data for (a). (c) The cell cycle distributions of the HepG2 cells after MTE treatment $(25 \mathrm{mg} / \mathrm{mL}, 50 \mathrm{mg} / \mathrm{mL}$, and $100 \mathrm{mg} / \mathrm{mL}$ ) were detected by FCM. (d) Quantitative data for (c). $n=3$.

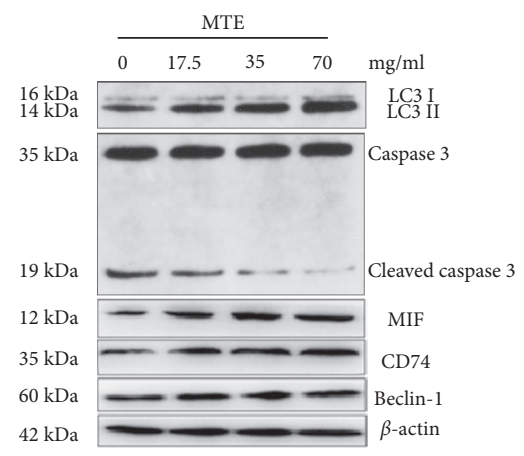

(a)

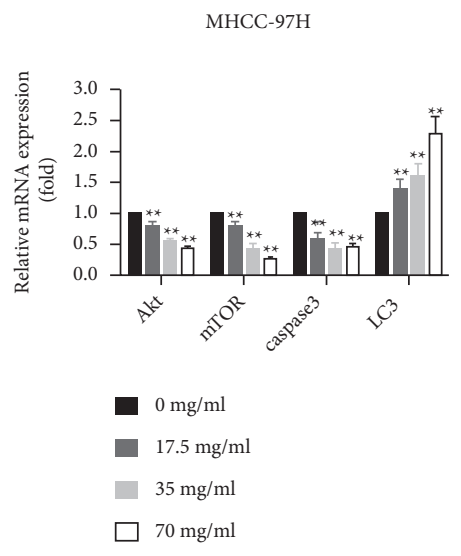

(b)
HepG2

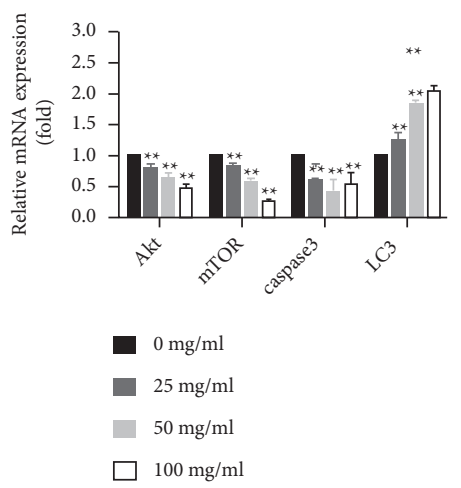

(c)

Figure 6: Continued. 


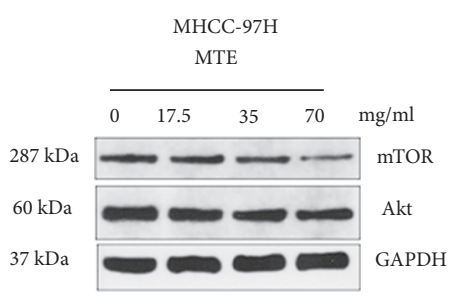

(d)

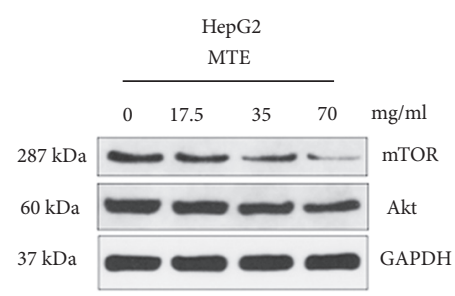

(e)

Figure 6: MTE induced the autophagy of HCC cells by inhibiting the Akt/mTOR pathway via MIF. (a) LC3 I, LC3 II, caspase3, cleaved caspase3, MIF, CD74, Beclin-1, and $\beta$-actin protein levels in MTE $(17.5 \mathrm{mg} / \mathrm{mL}, 35 \mathrm{mg} / \mathrm{mL}$, and $70 \mathrm{mg} / \mathrm{mL})$-treated MHCC-97H cells were examined by WB assay. (b) Akt, mTOR, caspase 3, and LC $3 \mathrm{mRNA}$ levels in MTE (17.5 mg/mL, $35 \mathrm{mg} / \mathrm{mL}$, and $70 \mathrm{mg} / \mathrm{mL})$-treated MHCC$97 \mathrm{H}$ cells were detected by qRT-PCR assay. (c) The mRNA levels for Akt, mTOR, caspase 3, and LC 3 genes in MTE $(25 \mathrm{mg} / \mathrm{mL}, 50 \mathrm{mg} / \mathrm{mL}$, and $100 \mathrm{mg} / \mathrm{mL}$ )-treated HepG2 cells were detected by qRT-PCR assay. (d) The mTOR, Akt, and GAPDH protein levels in MTE (17.5 mg/ $\mathrm{mL}, 35 \mathrm{mg} / \mathrm{mL}$, and $70 \mathrm{mg} / \mathrm{mL}$ )-treated MHCC-97H cells were detected by WB assay. (e) The mTOR, Akt, and GAPDH protein levels in MTE $(17.5 \mathrm{mg} / \mathrm{mL}, 35 \mathrm{mg} / \mathrm{mL}$, and $70 \mathrm{mg} / \mathrm{mL})$-treated HepG2 cells were detected by WB assay. $n=3$.

suggested that MTE induced autophagy in the HCC cells by suppressing the PI3K/Akt/mTOR signaling pathway.

Endogenous MIF has been reported to be an upstream regulator of the mTOR pathway, and Zhang et al. found that homocysteine induced autophagy-activated cell death by promoting MIF secretion and reducing mTOR expression [34]. Consistent with this, we found that treatment of the MHCC-97H and HepG2 cells with MTE promoted the expression of MIF and reduced the expression of Akt and mTOR, indicating that MTE might inhibit mTOR signaling via MIF to induce autophagy in the HCC cells. However, follow-up studies are required to verify the association between MIF and the mTOR pathway.

\section{Conclusion}

In summary, MTE inhibited the proliferation of the MHCC97H and HepG2 cells by inducing autophagy, apoptosis, and $S$ phase cell cycle arrest, and these effects might be related to MIF/mTOR signaling. Thus, MTE might be a potential therapeutic agent for HCC.

\section{Data Availability}

The data analyzed are available from the corresponding authors on reasonable request. Because of some confidential reasons, the participants of this study did not agree for their data to be shared publicly, and all authors do not wish to share the data with the database online before publication. Hence, supporting data is not available. However, the data used to support the findings of this study are available from the corresponding author upon reasonable request.

\section{Ethical Approval}

This study was approved by the Ethics Committee of the Second Affiliated Hospital of Xi'an Jiaotong University (Xi'an, China).

\section{Consent}

All participants signed an informed consent when recruited to provide basic and clinical information and blood samples.

\section{Conflicts of Interest}

The authors declare no conflicts of interest.

\section{Authors' Contributions}

Shuai Lin and Qianwen Sheng contributed equally to this work.

\section{Acknowledgments}

This work was supported by the International Science and Technology Cooperation Program Project, Shaanxi Province, China (2018KW-058).

\section{References}

[1] F. Bray, J. Ferlay, I. Soerjomataram, R. L. Siegel, L. A. Torre, and A. Jemal, "Global cancer statistics 2018: GLOBOCAN estimates of incidence and mortality worldwide for 36 cancers in 185 countries," CA: A Cancer Journal for Clinicians, vol. 68, no. 6, pp. 394-424, 2018.

[2] M. Sayiner, P. Golabi, and Z. M. Younossi, "Disease burden of hepatocellular carcinoma: a global perspective," Digestive Diseases and Sciences, vol. 64, no. 4, pp. 910-917, 2019.

[3] P. Erkekoglu, D. Oral, M. W. Chao, and B. Kocer-Gumusel, "Hepatocellular carcinoma and possible chemical and biological causes: a review," Journal of Environmental Pathology, Toxicology and Oncology, vol. 36, no. 2, pp. 171-190, 2017.

[4] M. Ronot, M. Bouattour, J. Wassermann et al., "Alternative response criteria (Choi, European association for the study of the liver, and modified Response Evaluation Criteria in Solid Tumors [RECIST]) versus RECIST 1.1 in patients with advanced hepatocellular carcinoma treated with sorafenib," The Oncologist, vol. 19, no. 4, pp. 394-402, 2014.

[5] K. O. Asafo-Agyei and H. Samant, Hepatocellular Carcinoma, StatPearls Publishing LLC., Treasure Island, FL, USA, 2020.

[6] P. Wang, J. Yang, Z. Zhu, and X. Zhang, "Marsdenia tenacissima: a review of traditional uses, phytochemistry and 
pharmacology," The American Journal of Chinese Medicine, vol. 46, no. 7, pp. 1-32, 2018.

[7] X. Wang, Y. Yan, X. Chen et al., "The antitumor activities of Marsdenia tenacissima," Frontiers in Oncology, vol. 8, p. 473, 2018.

[8] B. Xie, Y.-Y. Lu, Z.-H. Luo et al., "Tenacigenin B ester derivatives from Marsdenia tenacissima actively inhibited CYP3A4 and enhanced in vivo antitumor activity of paclitaxel," Journal of Ethnopharmacology, vol. 235, pp. 309-319, 2019.

[9] F. Wang, Q. X. Fan, H. H. Wang, D. M. Han, N. S. Song, and H. Lu, "Efficacy and safety of Xiaoaiping combined with chemotherapy in the treatment of advanced esophageal cancer," Zhonghua Zhong Liu Za Zhi, vol. 39, no. 6, pp. 453-457, 2017.

[10] H. Zhang, J. Zhang, H. Ding, R. Chen, and F. Liang, "Clinical value of Tongguanteng (Radix seu Herba Marsdeniae Tenacissimae) extract combined with chemotherapy in the treatment of advanced non-small cell lung cancer: a metaanalysis," Journal of Traditional Chinese Medicine, vol. 36, no. 3, pp. 261-270, 2016.

[11] K. Wu, Z. Zhu, Y. He, L. Huang, X. Yan, and D. Wang, "Efficacy and safety of Xiao Ai Ping injection combined with chemotherapy in advanced gastric cancer: a systematic review and meta-analysis," Evidence-Based Complementary and Alternative Medicine: eCAM, vol. 2019, Article ID 3821053, 12 pages, 2019.

[12] L. W. Ruan and Y. C. Deng, "Study on effect of Xiaoaiping in enhancing efficacy of neoadjuvant chemotherapy for breast cancer and its mechanism," China Journal of Chinese Materia Medica, vol. 40, no. 4, pp. 749-752, 2015.

[13] K. Liu, T. Tian, Y. Zheng et al., "Scutellarin inhibits proliferation and invasion of hepatocellular carcinoma cells via down-regulation of JAK2/STAT3 pathway," Journal of Cellular and Molecular Medicine, vol. 23, no. 4, pp. 3040-3044, 2019.

[14] C. Behrends, M. E. Sowa, S. P. Gygi, and J. W. Harper, "Network organization of the human autophagy system," Nature, vol. 466, no. 7302, pp. 68-76, 2010.

[15] Y. Liu and B. Levine, "Autosis and autophagic cell death: the dark side of autophagy," Cell Death \& Differentiation, vol. 22, no. 3, pp. 367-376, 2015.

[16] A. Yang, G. Herter-Sprie, H. Zhang et al., “Autophagy sustains pancreatic cancer growth through both cell-autonomous and nonautonomous mechanisms," Cancer Discovery, vol. 8, no. 3, pp. 276-287, 2018.

[17] A. V. Onorati, M. Dyczynski, R. Ojha, and R. K. Amaravadi, "Targeting autophagy in cancer," Cancer, vol. 124, no. 16, pp. 3307-3318, 2018.

[18] G. J. Yoshida, “Therapeutic strategies of drug repositioning targeting autophagy to induce cancer cell death: from pathophysiology to treatment," Journal of Hematology \& Oncology, vol. 10, no. 1, p. 67, 2017

[19] W. Yan, X. Ma, X. Zhao, and S. Zhang, "Baicalein induces apoptosis and autophagy of breast cancer cells via inhibiting PI3K/AKT pathway in vivo and vitro," Drug Design, Development and Therapy, vol. 12, pp. 3961-3972, 2018.

[20] Y.-J. Li, Y.-H. Lei, N. Yao et al., "Autophagy and multidrug resistance in cancer," Chinese Journal of Cancer, vol. 36, no. 1, p. 52, 2017.

[21] K. Matsuura, K. Canfield, W. Feng, and M. Kurokawa, "Metabolic regulation of apoptosis in cancer," International Review of Cell and Molecular Biology, vol. 327, pp. 43-87, 2016.
[22] Z.-X. Cao, Y.-T. Yang, S. Yu et al., "Pogostone induces autophagy and apoptosis involving PI3K/Akt/mTOR axis in human colorectal carcinoma HCT116 cells," Journal of Ethnopharmacology, vol. 202, pp. 20-27, 2017.

[23] K. Yoon, N. Kim, Y. Park et al., "Correlation between macrophage migration inhibitory factor and autophagy in Helicobacter pylori-associated gastric carcinogenesis," PLoS One, vol. 14, Article ID e0211736, 2019.

[24] I. Cotzomi-Ortega, A. Rosas-Cruz, D. Ramírez-Ramírez et al., "Autophagy inhibition induces the secretion of macrophage migration inhibitory factor (MIF) with autocrine and paracrine effects on the promotion of malignancy in breast cancer," Biology, vol. 9, no. 1, p. 20, 2020.

[25] N. S. Deen, J. P. Lee, and J. Harris, "Inducing and inhibiting autophagy to investigate its interactions with MIF," Macrophage Migration Inhibitory Factor, vol. 2080, pp. 147-158, 2020.

[26] O. El Bounkari and J. Bernhagen, "MIF and autophagy: a novel link beyond "eating"," Cell Research, vol. 22, no. 6, pp. 950-953, 2012.

[27] S. Xu, X. Guo, X. Gao et al., "Macrophage migration inhibitory factor enhances autophagy by regulating ROCK1 activity and contributes to the escape of dendritic cell surveillance in glioblastoma," International Journal of Oncology, vol. 49, no. 5, pp. 2105-2115, 2016.

[28] M.-Y. Wu, J. Fu, J. Xu, B. W. O’Malley, and R.-C. Wu, “Steroid receptor coactivator 3 regulates autophagy in breast cancer cells through macrophage migration inhibitory factor," Cell Research, vol. 22, no. 6, pp. 1003-1021, 2012.

[29] M. Aoki and T. Fujishita, "Oncogenic roles of the PI3K/AKT/ mTOR axis," Current Topics in Microbiology and Immunology, vol. 407, pp. 153-189, 2017.

[30] O. A. Bamodu, H. L. Chang, J. R. Ong, W. H. Lee, C. T. Yeh, and J. T. Tsai, "Elevated PDK1 expression drives PI3K/AKT/ MTOR signaling promotes radiation-resistant and dedifferentiated phenotype of hepatocellular carcinoma," Cells, vol. 9, no. 3, p. 746, 2020.

[31] N. Bassullu, I. Turkmen, M. Dayangac et al., "The predictive and prognostic significance of c-erb-B2, EGFR, PTEN, mTOR, PI3K, p27, and ERCC1 expression in hepatocellular carcinoma," Hepatitis Monthly, vol. 12, Article ID e7492, 2012.

[32] S. Menon, J. L. Yecies, H. H. Zhang et al., "Chronic activation of mTOR complex 1 is sufficient to cause hepatocellular carcinoma in mice," Science Signaling, vol. 5, no. 217, Article ID ra24, 2012.

[33] D. Tewari, P. Patni, A. Bishayee, A. N. Sah, and A. Bishayee, "Natural products targeting the PI3K-Akt-mTOR signaling pathway in cancer: a novel therapeutic strategy," Seminars in Cancer Biology, vol. S1044-579X, no. 19, Article ID 30405, 2019.

[34] Y. Zhang, Y. Zhang, J. Tang et al., "Oxymatrine inhibits homocysteine-mediated autophagy via MIF/mTOR signaling in human umbilical vein endothelial cells," Cellular Physiology and Biochemistry, vol. 45, no. 5, pp. 1893-1903, 2018. 